\title{
A socially inspired energy feedback technology: challenges in a developing scenario
}

\author{
Lara S. G. Piccolo ${ }^{1,2} \cdot$ Cecília Baranauskas $^{1} \cdot$ Rodolfo Azevedo $^{1}$
}

Received: 25 November 2014/ Accepted: 29 January 2016/Published online: 15 February 2016

(C) The Author(s) 2016. This article is published with open access at Springerlink.com

\begin{abstract}
Raising awareness of the environmental impact of energy generation and consumption has been a recent concern of contemporary society worldwide. Underlying the awareness of energy consumption is an intricate network of perception and social interaction that can be mediated by technology. In this paper we argue that issues regarding energy, environment and technology are very much situated and involve tensions of sociocultural nature. This exploratory investigation addresses the subject by introducing the design of a Socially-inspired Energy EcoFeedback Technology (SEET), which is composed of an interactive system to trigger and mediate collective savings and a tangible device as a public feedback. Results of an evaluation situated in the context of a school in a socially disadvantaged area in Brazil are discussed, shedding light on the sociocultural aspects related to the subject. The role of the SEET to motivate energy awareness collectively among the social group is assessed, as well as the design characteristics that contributed to that. Outcomes bring to light social aspects and dynamics that would hardly have
\end{abstract}

Lara S. G. Piccolo

lara.piccolo@open.ac.uk

Cecília Baranauskas

cecilia@ic.unicamp.br

Rodolfo Azevedo

rodolfo@ic.unicamp.br

1 Institute of Computing, State University of Campinas, Av. Albert Einstein, 1251, Cidade Universitária Zeferino Vaz, Campinas, SP 13083-852, Brazil

2 Knowledge Media Institute, The Open University, Milton Keynes MK7 6AA, UK been predicted, evidencing critical factors related to a socially inspired design approach in the energy awareness domain.

Keywords Motivation - Energy awareness ·

Eco-feedback · Collaboration · Social awareness

\section{Introduction}

Making people aware of the planet's natural resources limits has been a concern of contemporary society worldwide. This challenge encompasses understanding the way energy has been perceived and consumed to make visible, and sometimes to establish, the connection between daily activities and eventual consequences to the natural environment.

Brazil, the scenario of this study, has been considered a good example of clean energy generation to the world, and the average consumption per capita is still considerably lower than the world average (World Bank 2015). However, both environmental and economic reasons are recently boosting the need to invite the society to reflect about consumption habits and environmental consequences. Large investments in new power plants have been required (Brazil 2014), as well as more and more thermoelectric generation to supply the current demand. The society has experienced this impact in the bills. An official modification in the electricity bill launched in 2015 now informs the generation condition and the resulting variation in the monthly prices according to the need to use thermal generation beyond the predominant hydro-plant production (ANEEL 2014). The thermoelectric power increases the energy price (ANEEL 2014) and pollutes the air. Yet, a considerable part of the population may not even realise 
that this new reality is harmful not only monetarily but also to the natural environment.

As evidenced by quantitative surveys, the association between energy consumption and environmental impact is unclear or totally unknown by most people. Brazil was in the last position in a 17 countries ranking of a survey that inquired people about the correlation between environmental impact and energy consumption (Accenture 2010). Also, when questioned about factors with a negative impact on the environment, only $27 \%$ of Brazilians respondents mentioned individual energy consumption (Piccolo and Baranauskas 2013).

Still, our developing scenario has increased the purchase power of people, motivating them to buy more electric appliances, instead of conserving energy (Piccolo et al. 2013). We understand the society cannot be now deprived of comfort, safety, and any other welfare aspects related to electricity usage. But everyone, globally speaking, needs to become aware of consequences of daily choices to their own finances and to the environment.

Technology can play a role in promoting this new worldview relating energy consumption to the natural environment. Moreover, it can also support the development of a collective knowledge within the social group reality, guiding people's actions. This work addresses the subject by proposing the design of a Socially-inspired Energy Eco-Feedback Technology (SEET), which is composed by an interactive system to trigger and mediate collective savings and a tangible device as a public feedback.

The design and evaluation of the SEET targeted a social group in the Brazilian city of Sete Lagoas, where smartgrid technology has been recently deployed. This area has been selected as representative of the Brazilian reality in terms of average consumption of electricity and socioeconomic aspects. The situated study with the SEET took place in a public elementary school for a week, involving directly 24 students. Following the socially aware theoretic methodological framework (Baranauskas 2014), it intended to observe beyond the interaction of participants with the technology, considering also the influence in their daily life, as well as the impact in their social groups, surpassing a controlled research environment.

Understanding how people react and are impacted by the technology are key concerns when designing and evaluating technology in real life context, or "in the wild", as referred in recent HCI literature (Rogers 2011). Particularly with regard to energy consumption, real-world issues such as safety or the community organisation influence participants' perception, motivation, and actions (Dillahunt et al. 2009). The context addressed in this study demanded from researchers dealing with tensions of sociocultural nature, beyond the usual technical issues that happen in controlled environment experiments.

This paper sheds lights on how people perceived the technology, their motivations to use it, and whether/how the SEET design contributed to impact the social group during the intervention towards energy conservation. It is organised as follows: the next section summarises studies of technologies to raise energy awareness mainly in social groups. The socially aware approach is then introduced, setting the scene for describing the design and evaluation process of the SEET in the following section.

In the sequence, we present and discuss the study results as lessons learned from the technical and social perspectives, to finally conclude.

\section{Background and related work}

Investigations related to the potential of technologies to change the way people relate to energy have emerged in the last years in the human-computer interaction (HCI) domain, as for example by introducing concepts of psychology in the design to motivate individuals (Petkov et al. 2012) and to promote changes in behaviour (He et al. 2010). The literature review presented by Pierce and Paulos (2012), though, suggests a limitation in the current scenarios of investigations for not being representative in terms of social diversity. They are mostly situated in domestic environments of developed areas, mainly focused on aspects of providing feedback in the home environment (e.g. Petkov et al. 2012; He et al. 2010; Katzeff et al. 2012). In line with Dillahunt et al. (2009), in our perspective, beyond personal values and willingness, culture and the socio-economic contexts are also external forces that strongly influence perception and consumption of energy (Piccolo and Baranauskas 2011).

Design and evaluation of artefacts for raising energy awareness of groups have been found in the literature involving employees in workplaces, promoting collaboration among neighbours and including students in energysaving initiatives.

In the workplace, Jönsson et al. (2010) used three oversized torches to project real-time energy consumption statistics on the floor of a factory. The evaluation indicated the importance of placing the installation in sociable areas, such as those close to a coffee machine, and suggested that the situated engagement is not a guarantee of further online engagement with the subject. Holmes (2007), instead, proposed an animated public display representing the building footprint. A sequence of images with trees varying between green and grey meant the amount of water, energy, and the equivalent $\mathrm{CO}_{2}$ emitted according to the 
building automation system. The long-term impact of the installation was not discussed.

Motivating savings among neighbours and consequently reducing the demand for energy generation is the aim of Boucher et al. (2012), who evaluated different design alternatives, such as displaying daily gathered consumption data on the street. During the month of the study, the consumption was reduced in $15 \%$.

Investigations involving students typically relied on competition to engage participants. In the study by the Computer Technology Institute (2012) in Greece, 50 schools competed for reducing their buildings consumption. The schools ranking is presented in a website that also supports saving energy with recommendations for teachers and students. In Brewer et al. (2011) and Johnson et al. (2012), the impact of competition on energy savings was evaluated in a students' residence in Hawaii. The strategy promoted savings, but also has led to unsustainable behaviour due to the strong will of winning the competition (Johnson et al. 2012).

The study of Kuznetsov et al. (2010) evaluated feedback of water consumption integrated with sensors to encourage savings both in public faucets and private showers. The display promoted $30 \%$ of decrease in average shower times, but it increased consumption in public faucets due to the interest of people for the technology in use.

Understanding how people relate to energy in developing scenarios was targeted by Dillahunt et al. (2009) in low-income areas in the USA, and in India by Vyas (2012), the latter focusing on sustainable domestic practices. In Brazil, Cohen et al. (2005) studied domestic energy consumption, but not relying on any technology to raise energy awareness.

Similarly to this study, a smart-grid deployment was also recognised by Stragier et al. (2013) as an opportunity to promote energy awareness. The authors argue that without the smart meters, people need to rely only on the monthly bill and the traditional meters to monitor the consumption, which is not always physically accessible and subject to misinterpretation (Stragier et al. 2013).

In this paper we argue that the issues regarding energy, environment and technology are very much situated and involve tensions of sociocultural nature. Underlying the awareness of energy consumption is actually an intricate network of perception and social interaction that can be mediated by technology. In the next sections, the design of technology aiming at raising energy awareness collectively is presented. Results of an evaluation situated in a school in a socially disadvantaged area are discussed, shedding light on the socio aspects related to its use.

\section{The socially aware design of the eco-feedback technology}

The Socially-inspired Energy Eco-Feedback Technology (SEET) was designed for and evaluated by users in a social group in the city of Sete Lagoas, in line with the socially aware computing approach (Baranauskas 2014). This approach to design goes beyond conceiving a system simply based on technical requirements. Design is understood as a dynamic process originated in the society, crossing informal aspects (e.g. values, beliefs) and formal aspects (regulation, for instance), towards the construction of a technical system. The technical system, on the other hand, impacts the formal and informal levels, towards influencing the society. Figure 1, adapted from Baranauskas (2014), illustrates this approach to design.

The construction of the system in the technical level demands the articulation of meanings among the social group in their informal and formal levels, as well as artefacts to mediate this communication (Baranauskas 2014). In line with this approach, the artefacts we have applied to design are mostly grounded on the organisational semiotics, a discipline for understating information in a social context (Liu 2000).

People's motivations for taking part in studies that impact their life tend to vary (Rogers 2011). Adding a motivational perspective to the SEET design/evaluation, the self-determination theory (SDT) (Deci and Ryan 1985) has been adopted as a main reference to understand this force that guides humans' actions. Beyond intrinsic aspects, the SDT also considers external forces, those culturally influenced, as sources of motivation.

\subsection{The design process}

The SEET design was informed by motivational and sociocultural aspects, following these steps:

(1) To understand the problem situated in our context, guidelines of residential eco-feedback design from the literature were interpreted considering how people

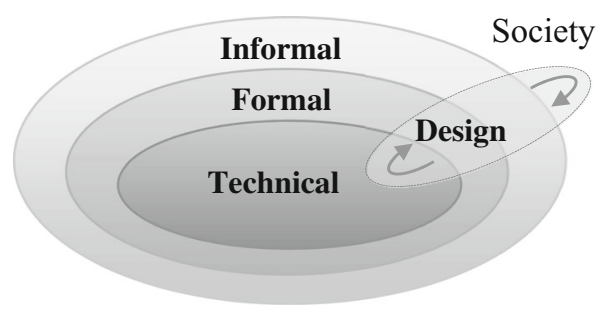

Fig. 1 Socially aware design approach. Adapted from (Baranauskas 2014) 
perceive energy in our scenario, willingness to monitor and reduce consumption, etc. This perspective of our scenario was mostly built based on key stakeholders' (e.g. utilities staff) experience. The study resulted in a set of preliminary design requirements (Piccolo and Baranauskas 2011);

(2) The preliminary requirements were reviewed with the lenses of the self-determination theory (Deci and Ryan 1985), suggesting aspects that should be strengthened in the design to promote motivation (Piccolo and Baranauskas 2012a, b);

(3) The metaphor of a tree connecting energy and the environment and other design elements resulted from a workshop conducted with HCI students in the role of designers (Piccolo and Baranauskas 2012a);

(4) The analysis of the Brazilian scenario according to the 10 areas of culture by Hall (1959) resulted in implications to design, such as highlighting the importance of contextualised (and popular) elements to empower users to protect the environment (Piccolo et al. 2012);

(5) Analysis of a quantitative survey that inquired people in the area of Sete Lagoas about the way they relate to energy, typical appliances, consumption habits, etc. The analysis was based on the semiotic ladder, an organisational semiotics artefact (Liu 2000), leading to a social and collaborative architecture and to design guidelines such as "informing about the need to build new dams and power plants to supply energy demand", and "making energy tangible" (Piccolo and Baranauskas 2013).

(6) Analysis of behavioural norms from the organisational semiotics perspective and identification of intended behaviour promoted by the technology: "ALWAYS, when establishing a collective action THEN users MUST discuss and agree about each user and his/her family commitment", is an example of an intended social norm. Results of this behavioural analysis led to whole concept of the SEET (Piccolo et al. 2013)

Figure 2 illustrates the steps of the SEET design process. The requirements in step 1 were refined in the step 2. Together with steps 3-6, the SEET was conceived and designed.

\subsection{The Energy Tree}

The energy tree was created to tangibly represent energy savings. The seven branches of a LED light tree, which is solar powered, are lightened on progressively, representing accumulated results of collective energy savings.

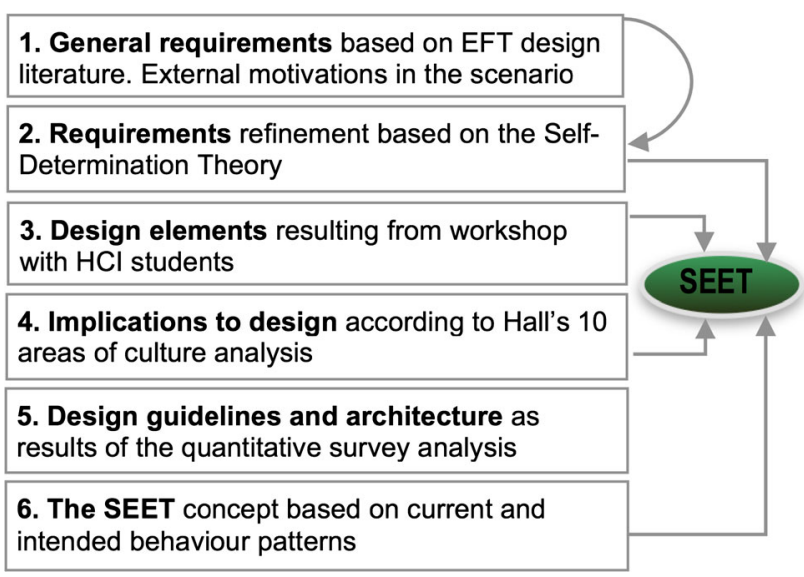

Fig. 2 Steps of the SEET design
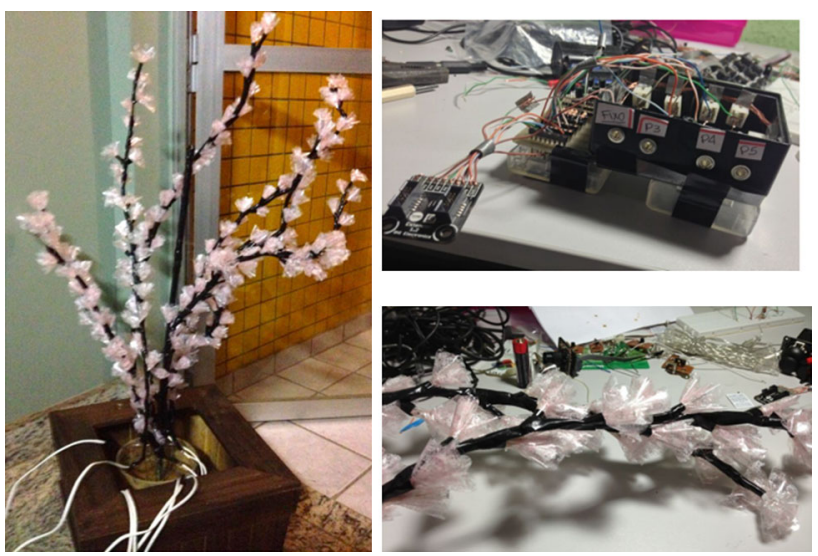

Fig. 3 Handcrafted tree

The tree was handcrafted. Typical Brazilian pastry cups compose the flowers. The controller is based on the Microsoft Gadgteer Fez Spider Kit (Fig. 3). This device was then joined to a public interactive system designed for gathering areas constituting the SEET.

Through the interactive system, groups of users establish the level and the number of days of an energy saving challenge. On a daily basis, they check their achievements represented both by the number of branches lighted on and by the number of flowered branches in a virtual tree. Even though proposing a challenge, a typical game characteristic, the interactive system did not intentionally promote any sort of competition among the participants.

\subsubsection{Interacting with the Energy Tree}

Users name the group and choose a tree among popular species in the region to represent them. Then, they establish their challenge by determining the quantity of participant households (from 5 to 10), the number of days for the 


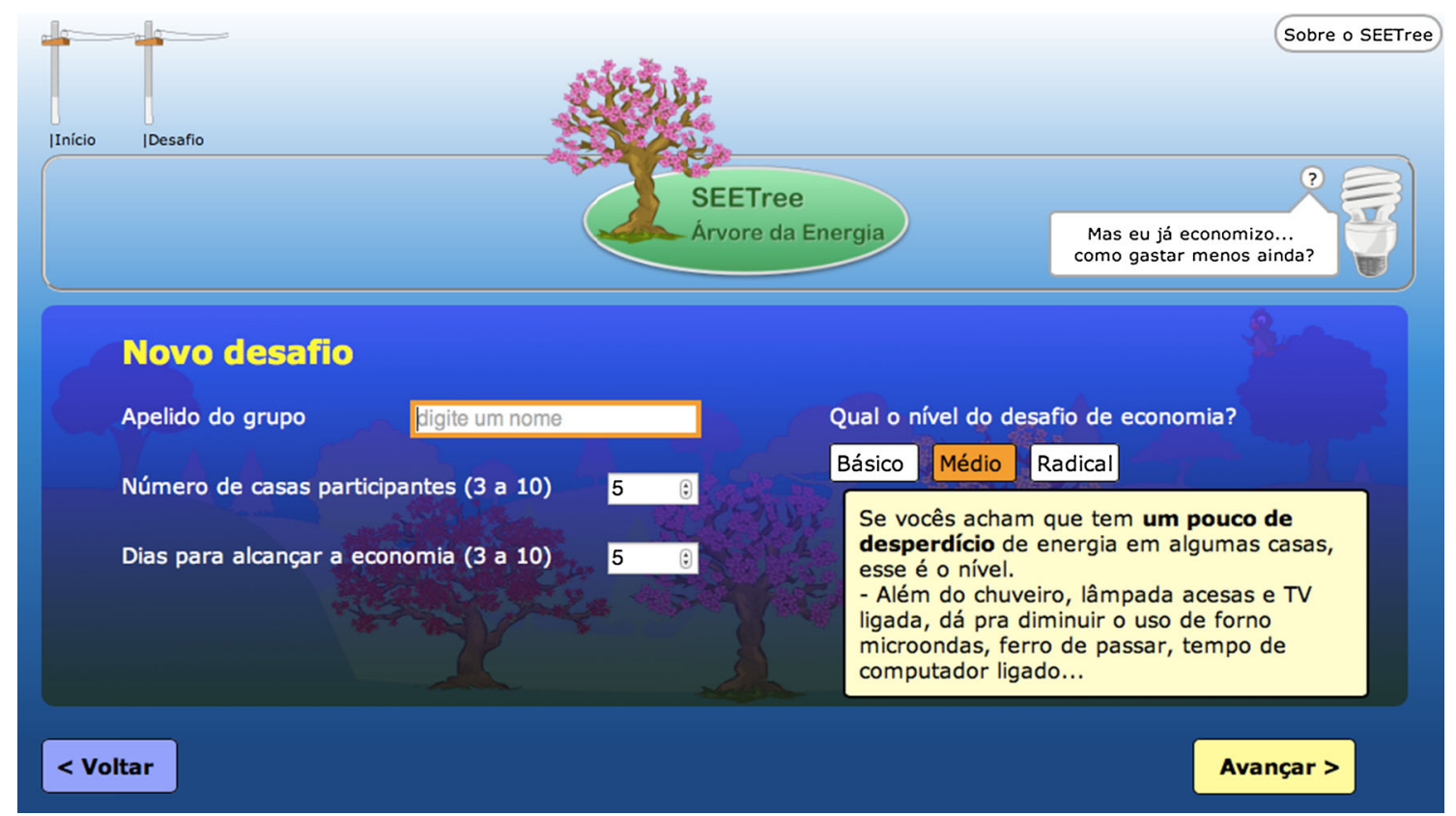

Fig. 4 Challenge creation UI (in Portuguese)

challenge (from 3 to 10), and the level of savings aimed to be achieved, as illustrated in Fig. 4.

Users are guided by a description that mentions common appliances in the home scenario and how they are typically used. It is expected that the participants discuss their perception of their household consumption to define the parameters consensually. They also associate the energy meter numbers to the group. Those with smart meters at home are identified and will have the consumption automatically updated during the challenge.

By clicking on the bulb, an always-on link (Fig. 4), the more interested users access hints and extra information, i.e. about the smart meters functioning, estimated number of trees needed to compensate the $\mathrm{CO}_{2}$ emitted monthly to light the city, etc.

Every morning during the challenge period, the households' consumption is updated according to the utility's database. A manual input of readings is also available for those participants without the smart meters installed. As a matter of exception to overcome eventual missing readings, a sequence of zeros typed as the daily consumption set a symbolic saving (the daily baseline reduced by $1 \%$ ).

The status of the tree is then updated comparing the current consumption in the day with the baseline (based on the previous month). The reduction is then translated as lights of the tree. The current status of the tree can be checked online and also via webcam, as illustrated in Fig. 5. Users can also publish their savings results in the project Facebook page.
Beyond their own tree, users can check the forest status, with three groups' tree randomly presented. As illustrated in Fig. 6, the water level in the forest representing "the new dam" means savings results of all the groups, promoting the idea that everybody needs to contribute to effectively protect the environment.

\section{The SEET situated study}

The situated use of SEET aimed to observe: (1) how participants make sense of the SEET; (2) whether the SEET was effective to promote a new perception of energy consumption within their social group.

\subsection{The scenario}

The study took place in Sete Lagoas, a city with more than 220,000 inhabitants and Human Development Index (HDI) of 0.76 , considered 'high human development' for a developing country in the HDI categorisation, similar to the national index in Brazil (IBGE 2015; United Nations 2015). In average, people in this area tend to consume around $150 \mathrm{kWh}$ of energy monthly, the same of the Brazilian average. Benefited with a mild temperature, air conditioner and heating, the main villains of domestic energy consumption around the world are not usual in this area. The energy is typically consumed by TVs (present in $97 \%$ of the households), electric showers (in $79 \%$ of 


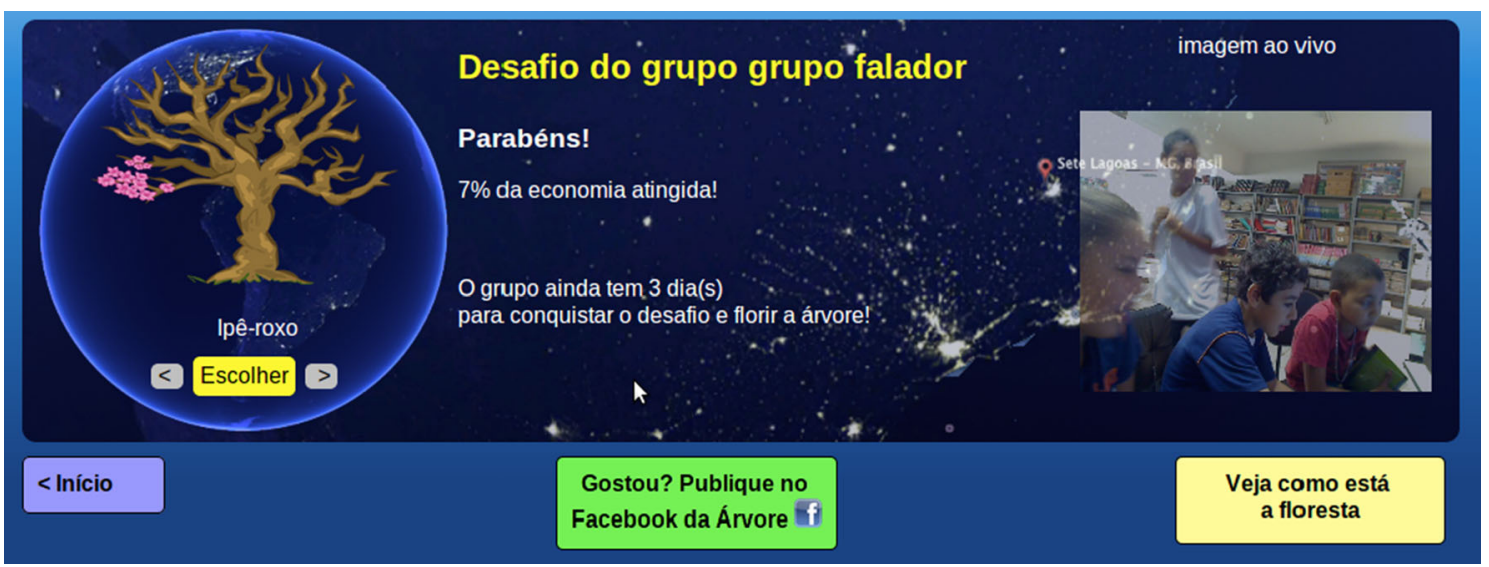

Fig. 5 Tree status and webcam visualisation (in Portuguese)

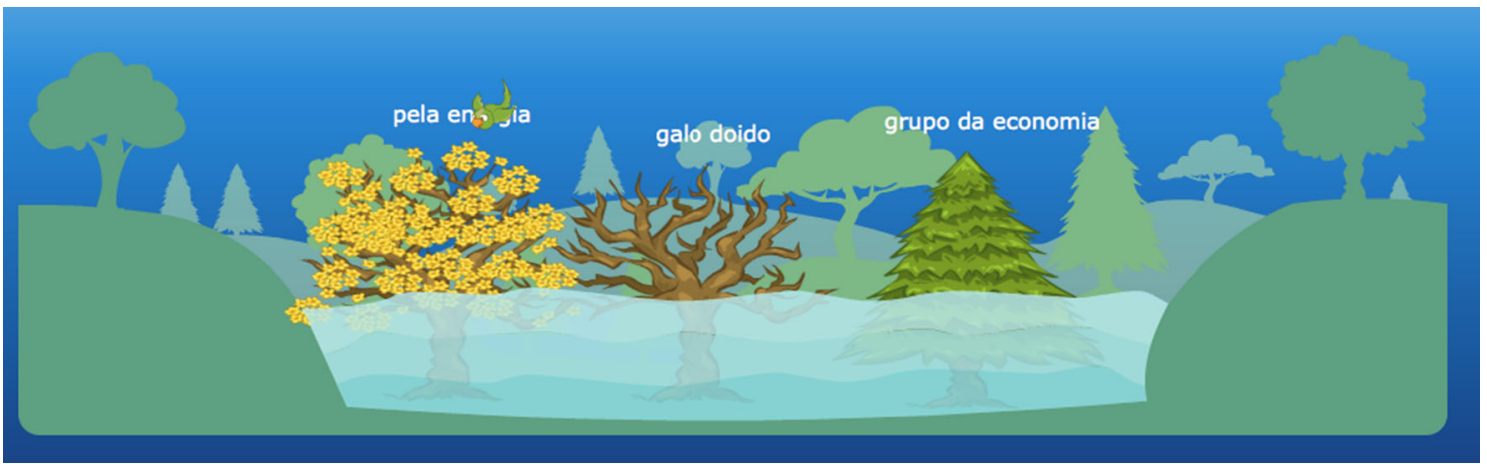

Fig. 6 Forest user interface, with results of 3 groups

the households), fridges, mobile phones, etc. (Piccolo and Baranauskas 2013). As a matter of comparison, the average monthly in the USA is $1000 \mathrm{kWh}$ and in the UK is $500 \mathrm{kWh}$ (World Bank 2015).

The study took place in a public elementary school centrally located in the city, core of a smart-grid project's geographic area. Most of the students live in the surroundings, sharing the similar socio-economic background and potentially having new smart meters installed at home, according to the project directives.

Illegal connections for stealing energy exist in the area, but not in a critical level as some other areas in Brazil, according to the energy provider's perspective (Piccolo and Baranauskas 2011). The region where the school is located, though, is considered at social risk due to drugs traffic, which interferes in the community life.

\subsection{Participants}

Around 40 students from 8 to 11 years old were invited to participate by a letter sent to their parents or guardians. A total of 24 children returned a signed authorisation also stating their last month consumption (to be used as baseline of savings), and the energy meter identification to be linked with the smart-grid programme. Parents were explicitly informed that their home consumption would not be published and that the children should count with the family collaboration during the week of activity related to energy conservation.

\subsection{Setting up the SEET}

Setting up the saving challenges accordingly is crucial for participants to make sense of the SEET. Proposing too ambitious reduction target may lead users to give up, and too easy might not incite critical thoughts.

The survey analysed by Piccolo and Baranasukas (2013) provided statistics around sociocultural data and energy consumption patterns, essential information to setup the experiment. Simulations considering the typical consumption in the region and concrete possibilities of reduction were taken into account to determine possible levels of savings.

The low consumption level (approximately $5 \mathrm{kWh}$ per day) in addition to the short-time nature of this experiment, suggested that it would be impossible to be precise in terms 
of savings calculation. Just a symbolic level of savings could be expected.

Following the consumption simulation results, three levels of savings considered feasible were proposed: Basic level-3\% of reduction, Medium level-4\%, and Radical level-6\%. In an average house example (150 $\mathrm{kWh} / \mathrm{monthly}$ ), the radical level means $1.2 \mathrm{kWh}$ less in the 4 days of the challenge.

Instead of assessing savings, raising awareness was the main target of the intervention, so it was not considered a critical constraint. In addition, as observed by Neustaedter et al. (2013), people in general usually think in their consumption at a higher level.

\subsection{Schedule}

The SEET was installed in the school's library (Fig. 7) for the whole week. A TV was used as a big monitor for the interactive system. Besides interacting with the system, the students participated of group activities and system evaluations in an informal and enjoyable way, combining some few individual activities with group discussions. Details on the methods/artefacts applied will be provided in next section.

From Monday to Friday, the activities followed the following script:

Day 1: A focus group discussed the need of energy for performing daily activities, current behaviour towards savings within the family, and identification of energy wasting. They were also asked to discuss about the functioning of the hydro-plant, thermoelectric generation and how they impact the environment. After the focus group, the teacher formed groups of 4 or 5 people randomly chosen to set the saving challenges. The students received three tangible artefacts: (1) a list of actions that consume an average of $1 \mathrm{kWh}$, e.g. having a

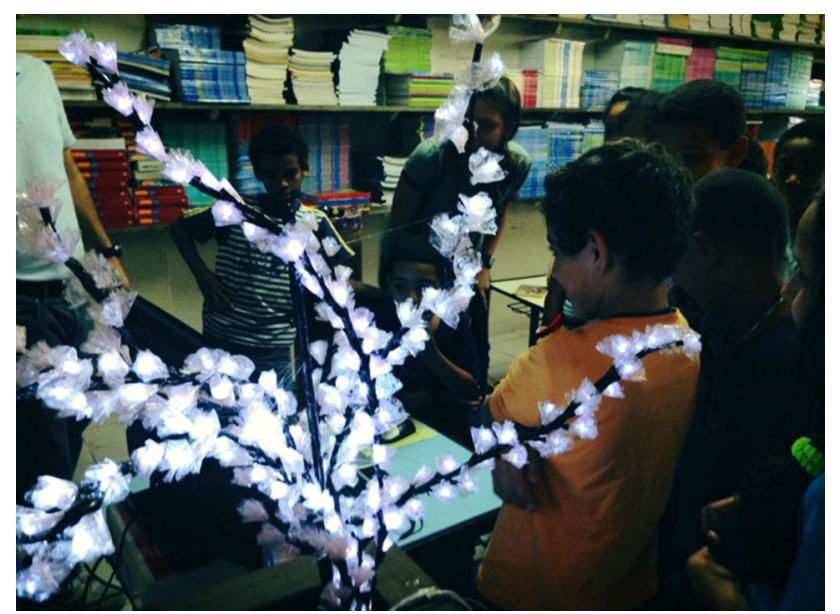

Fig. 7 Tree in the school library 17-min shower, $10 \mathrm{~h}$ of TV, 45 min of hair dryer; (2) a form for checking the actions they were committed to perform; (3) a form for writing down daily readings from the meter for those who did not have the smart ones.

Day 2: The saving challenges creation. The interaction with the SEET was observed by the researcher and evaluated with participants in terms of design elements. Day 3: Participants checked their tree status and input the daily readings. The groups discussed their motivations by answering together a questionnaire on their reasons (extrinsic and intrinsic) to be part of the study. Day 4: After entering new readings and checking the tree status, the groups provided feedback in terms of emotional response to the SEET and individually responded to a motivational questionnaire. A sample of parents/guardians was interviewed regarding the influence of the activity in the students' family behaviour. Day 5: After entering the last reading, the groups checked their final performance in the challenge. Then, they answered a short questionnaire about their perceptions of the activity as a whole. A new focus group with all students discussed consequent changes in the family behaviour during the week, with some testimonials of participants. The school pedagogical coordinator and a teacher were then interviewed evaluating the study setup from the learning perspective.

\section{Results of the study}

The activities were executed as previously described. As follows, we report results of the study in terms of: (1) Initial perceptions of energy; (2) Interaction with the SEET, including emotional responses; (3) Participants' motivations; (4) Engagement with the activities; and (5) Raising energy awareness.

\subsection{Initial perceptions: connecting energy to water}

In line with results of the quantitative survey that pointed out the weak connection between energy consumption and the natural environment (Piccolo and Baranauskas 2013), the initial focus group results showed that people in this scenario relate energy to water, but the way this connection happens is unclear to them: "it is going to have more remaining clean water if we save energy". Participants did not know how to explain the energy generation process and argued that by saving energy they save water. The dams and new flooding areas, traditionally part of hydro-generation in Brazil, were not mentioned. The image of a thermoelectric power plant was not recognised by them as a source of energy. 
Participants did not identify high levels of energy waste at home. Keeping the TV on when leaving the room and constantly opening the fridge are examples of frequently mentioned waste. The electric shower, the typical villain in the energy bill, was not cited in the focus group.

\subsection{Interaction with the SEET: the impacts of a collective system}

The fact of being a collective and collaborative system setting required from participants some negotiation for interacting and setting the challenge. Choosing the name of the group and the type of tree were the initial aspects discussed. All the groups changed the default image of the tree, and the selection criterion was having an exclusive one. They wanted to create their identity.

The expected negotiation among the participants to set up the challenge and the consequent reflection on their households' consumption happened. All groups started by arguing pro the radical level of savings. All but one group changed to the medium level when they realised that the results would not rely only on their effort, but requires the family collaboration. "But we consume few", argued a participant reading the guidelines from the user interface on suggested level for the typical appliances usage.

They spontaneously shared the control between two people in each group; one controlled the mouse and other the keyboard, and most of them passed the keyboard to the person at the moment to type their own name and their energy readings. However, this aspect was the only suggestion of improvement by the participants in the study when the activity finished: "I think everybody should use the computer the next time”.

When invited to explore the bulb linking to short hints (see in Fig. 4), interaction that did not happen spontaneously; a typical reaction was that one participant read the content loudly to the others, evidencing their understanding on the collective (and collaborative) approach.

The image of a flooded forest represented the need of everyone's contribution for protecting the environment effectively (Fig. 6). Initially they were intrigued by the representation, but when reminded of the hydro-energy generation process, they quickly made sense of the collaborative meaning.

The tree as a tangible and public feedback became the absolute symbol of the study, which was constantly referred by the teacher and students as "the tree activity". The novelty aspect of the technology called children's attention and also instigated their curiosity to understand the functioning. "How does the tree know how much we consume?" was an example of questioning from kids to the researcher.
Some participants came to the physical tree to check whether the number of branches was matching the virtual tree results. However, in the last two days of the activity, they needed to be reminded of the presence of the physical tree. The interactive system and the social aspect of the activity (collaboration and the competition that spontaneously emerged) became certainly more important to them than the tangible device itself.

\subsubsection{Emotional response to the user interface}

Appropriate user interfaces should lead to positive emotional response from users (Hayashi et al. 2013). We then evaluated the emotional response to the SEET and its design elements.

The Self-Assessment Manikin-SAM (Bradley and Lang 2000), a pictographic questionnaire, has been applied in HCI literature to assess the affective quality of user interfaces (Chorianopoulos and Spinellis 2006; Hayashi et al. 2012, 2013; Rodrigues et al. 2014). It evaluates three dimensions of emotions: valence, representing a positive or negative feeling caused by the experience; arousal that means the level of excitement or boredom; and dominance, the feeling of being in control of the situation.

In groups, the participants answered the SAM questionnaire considering their experience interacting with the SEET. Results were highly positive, excepted by the arousal, which received lower values possibly due to the interaction in groups of 4-5 people, limiting the possibility of everyone to be in the command of interaction.

Figure 8 presents the three dimensions of the assessment in a 1-5 scale, in which 1 represents the most negative response and 5 the most positive.

Similar pictographic figures used in the assessment with SAM were now applied to individually evaluate design elements. Figure 9 exemplifies the artefact.

The objects of design evaluation were: the full home page, the different types of trees, including an "empty one" with no flowers, and the physical one. Results confirmed the positive feelings towards the system by the evaluation of the full home page, as illustrated in Fig. 10. As expected, the "empty" tree received a negative response, but the physical tree was no better evaluated than the virtual ones, suggesting that users considered the setting as a whole.

A positive response when using the interactive system is important to evaluate the design; however, it does not provide the whole picture in terms of the external aspects involved in the interaction with the SEET. For this reason we also performed some motivational assessment, described as follows. 
Fig. 8 Results of the SAM evaluation

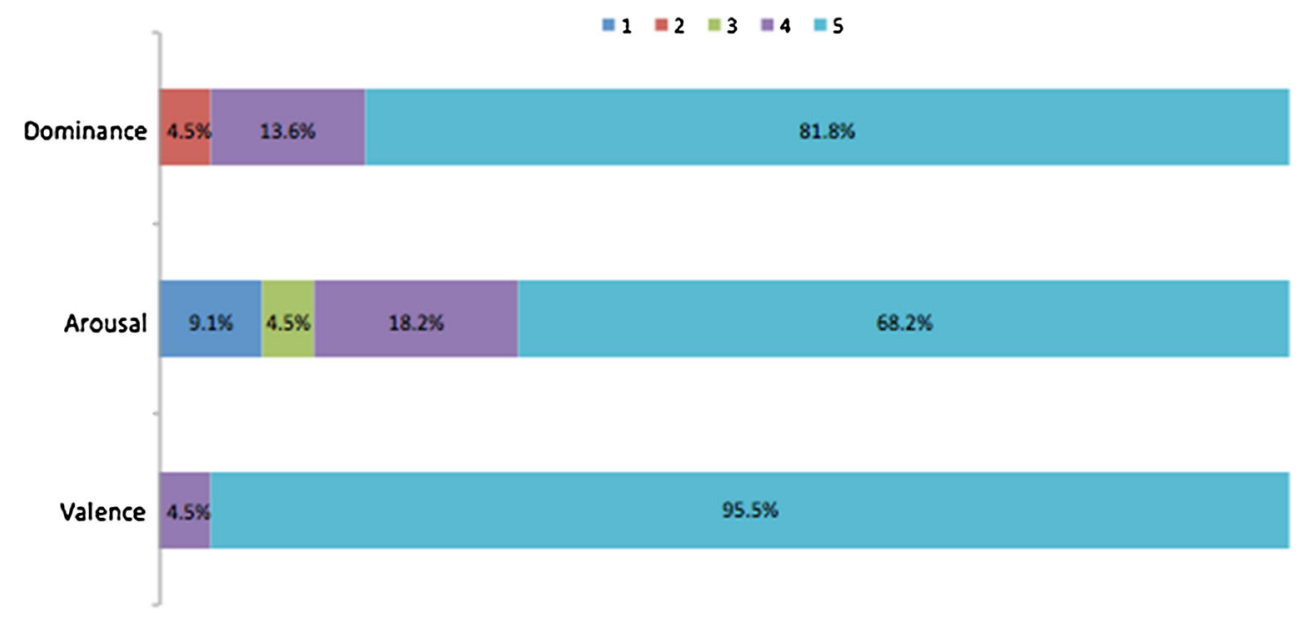

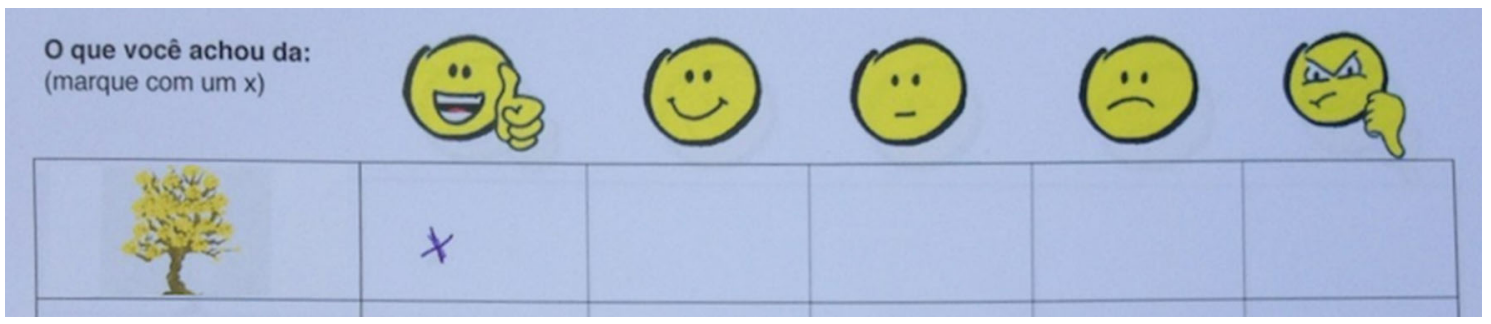

Fig. 9 Example of evaluation of design elements

Fig. 10 Results of design elements evaluation

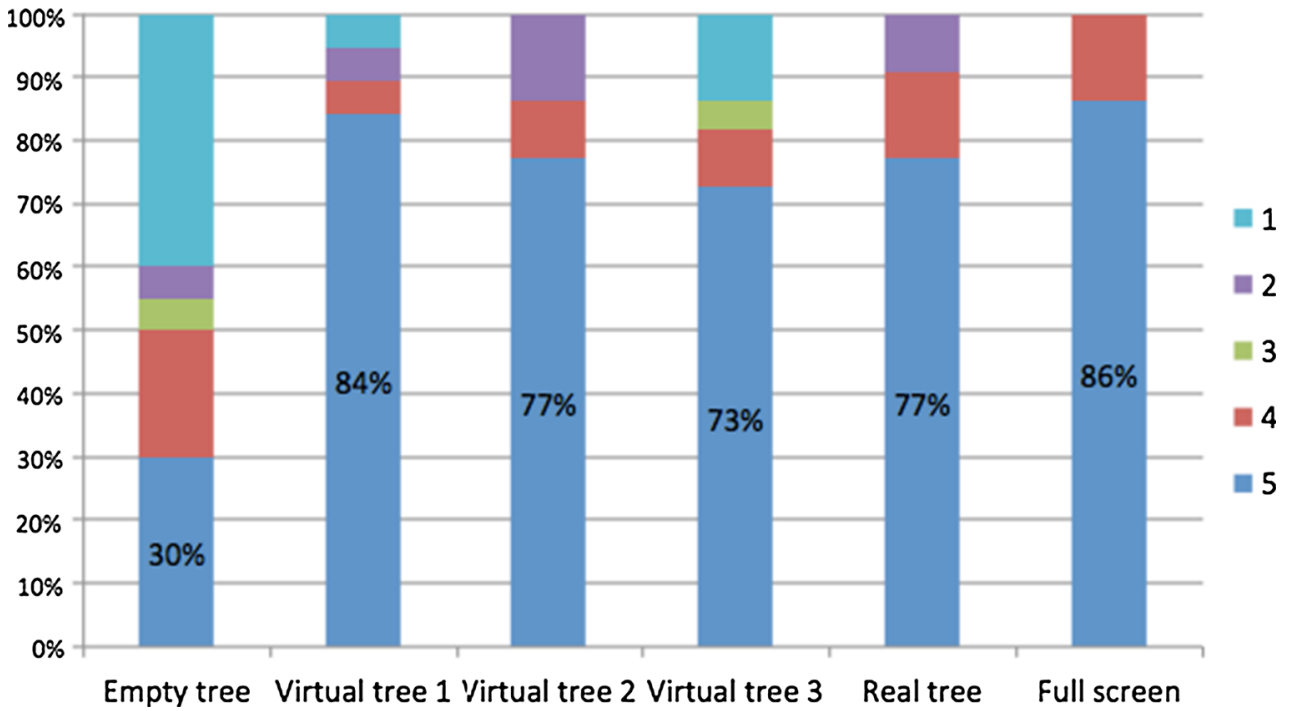

Scale-EMS (Guay et al. 2010) and the Individual Motivation Inventory-IMI (SDT 2014).

Even though acknowledged that the number of participants would not be enough to deliver statistically precise results, understanding how these motivational assessments could contribute to design was also an indirect goal of the study. Results were expected to suggest the most evident motivational forces (or the lack of them) in play. The 
questionnaires were translated to Portuguese, although not being formally validated according to the psychometric approach due to the small sample size.

The EMS (Guay et al. 2010) was proposed to assess different types of motivations in young elementary school children from 8 to 11 years old, checking whether they are acting: (a) intrinsically motivated (congruent with values and needs); (b) identified regulated, when they identify externally the reasons for performing behaviour, such as the importance of learning; and (c) controlled regulated, as a response to internal pressures such as obligation or guilt. The groups had to choose among (1) always no, (2) sometimes no, (3) I don't know, (4) sometimes yes, and (5) always yes, in a two-part response. First they say yes or no, then indicating if always or sometimes. "I don't know" was the last option if the group does not provide any answer, which did not happen. Results revealed a high score of (a) intrinsic motivation (mean $=4.6$ ), which is related to enjoyment and interest; also the high level of (b) identified regulation (mean $=4.7$ ), reflecting learning as an present external reason for using the SEET; and (c) a lower controlled regulation, or a sort of pressure associated with the performance to achieve a reward, or to impress or satisfy other people $($ mean $=3.7)$. The complete tabulation of EMS is available in "Appendix".

The IMI was applied individually, adapted from the nine-item version with three subscales: interest/enjoyment, perceived competence and pressure/tension (SDT 2014). Interest/enjoyment is a self-report measure of intrinsic motivation; perceived competence is also a positive predictor of intrinsic motivation related to how adequate the interaction was to participants' skill; and pressure/tension a negative predictor of intrinsic motivation related to external factors.

Although also limited in statistical terms, the results of IMI suggested the participants had, in average, highly intrinsic motivated behaviour (6.48 of 7), considered the activity suitable and challenging in a reasonable balance (6.09 of 7), and felt low external pressure (2.98 of 7). The results of IMI as summary statistics are presented in the "Appendix".

\subsection{Engagement}

Unexpectedly, only two participants out of the 24 had the smart meters installed in the households, requiring from the majority to visit the meter every morning for taking notes of the readings and manually enter the numbers during the challenge.

Half of the students made all the readings, while only four skipped all of them. Those who visited the meter for the readings not always took to the school consistent annotations. The main reason of the misreading was an

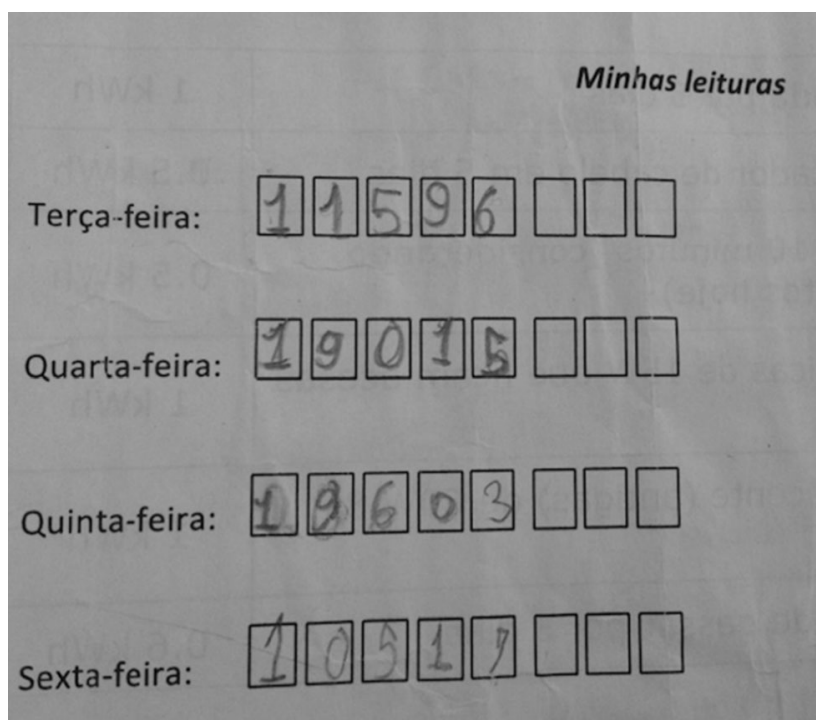

Fig. 11 Example of inconsistent reading note

unexpected diversity of meters equipment with different number of decimal places. The paper form and the user interface were designed to fit a digital meter with three decimal places, informed by the utility as the only one existing in that region. Figure 11 illustrates an example of inconsistent notes. The numbers were supposed to be incremented in few $\mathrm{kWh}$ day by day due to the cumulative aspect of the meter.

\subsubsection{Competition (and cheating) and comparison}

The children expressed extreme disappointment (one even cried!) when informed that their readings were eventually wrong. When the alternative input (the sequence of zeros) needed to be typed to overcome it, participants felt like failing. It was not the only reason why children started cheating. Some pretended they memorised the readings and created false numbers to not be blamed by others as the one that caused the group to fail. Some participants wrote down lower numbers than previously and also tried to enter wrong numbers on behalf of other groups.

Known as a controversial motivational strategy from literature (Brewer et al. 2011; Johnson et al. 2012), the competition among groups was not promoted in any circumstance. It emerged as a clear a motivation for them to feel engaged. Not only winning the competition was valued as important, but having a prize or reward too. Frequently, participants asked: "Will those who completed the tree earn something?". The teacher also suggested providing some symbolic award to fit their expectation. A real seedling of flower was then offered to the groups that completed the tree, and all participants received a thankyou note with a small gift. 
As stated by Froehlich et al. (2010), the social comparison was noticed as an important strategy to evaluate individual performance. Participants constantly compared their numbers among the group during interaction and regularly navigated through the system to check the tree of other groups.

Proud of their achievement, the students that completed the challenge wanted to show the lighted tree to everyone.

\subsubsection{Engagement: a mobile target}

The socio-economic reality of the considered scenario had announced the possibility of low level of savings during the study. Indeed, the few appliances and controlled use they make of them in most of the houses made it unfeasible to precisely assessing reductions in the challenge period. Some students reported changes like "I'm now disconnecting the mobile phone from the recharger as soon as it is recharged", an important collective action but not enough to be measured individually. Short-term experiments are also vulnerable to external factors, such as a blackout in some areas of the city, as happened during the activity, possibly lowering most of the consumptions.

These facts, in addition to the unreliable reading data participants brought, have led to a change in the criteria adopted to turn on the branches of the tree. Participants' "engagement" with the activity was considered to calculate their final performance instead of the savings. Engagement here is understood as their participation beyond interacting with the system, but bringing their daily readings and getting involved with the debate in and out of the school. The group that most contributed with the readings was the reference to light on all the tree branches and to calculate proportional results for the other groups.
Table 1 associates groups' participation (percentage of readings students brought from home) with the mean of their motivational assessments (both EMS and IMI) and the SAM application, as an attempt to correlate these factors. G2 and G5 were the groups that completed the challenge with the whole tree lighted on, and G3 was the group with lower participation.

Probably for taking into account the group perception, the EMS seemed to better represent engagement compared to the IMI, which was applied individually for a small sample, not representative enough to express a collective result.

The high level of controlled regulation of G2 suggests the importance of rewards expressed by the participants, evidencing that, beyond intrinsic motivation, external forces also play a significant role to engage students, especially in such initiative that requires effort beyond the classroom.

Results of SAM represent the overall experience of each participant. It reinforces the positive view of the technical artefacts by the high levels of valence and dominance, which in line with competence of IMI reflected the adequacy of the system to participants' abilities. The low level of arousal of G5 has a possible explanation by their explicit interest to be in control of the interaction. In addition, this group also expressed the highest level of tension when using the SEET.

\subsection{Social impact: raising energy awareness}

In the final focus group, students reported eventual changes in their households during the challenge. Turning off the lights and reducing the time of keeping the TV on were the
Table 1 Synthesis of motivation evaluation by groups

\begin{tabular}{|c|c|c|c|c|c|c|}
\hline & & G1 & G2 & G3 & G4 & G5 \\
\hline Participation & & $67 \%$ & $80 \%$ & $33 \%$ & $60 \%$ & $73 \%$ \\
\hline \multicolumn{7}{|l|}{ IMI } \\
\hline \multicolumn{7}{|l|}{$(1-7)$} \\
\hline & Mean of interest & 7.0 & 6.4 & 6.3 & 6.6 & 6.3 \\
\hline & Mean of competence & 6.0 & 5.8 & 5.4 & 5.0 & 5.4 \\
\hline & Mean of pressure & 2.9 & 3.0 & 3.3 & 4.1 & 4.6 \\
\hline \multicolumn{7}{|l|}{$\begin{array}{l}\text { EMS } \\
(1-5)\end{array}$} \\
\hline & Intrinsic motivation & 5.0 & 4.7 & 3.3 & 5.0 & 5.0 \\
\hline & Identified regulation & 4.7 & 5.0 & 4.3 & 4.7 & 5.0 \\
\hline & Controlled regulation & 4.0 & 5.0 & 2.0 & 3.0 & 4.3 \\
\hline \multirow{2}{*}{\multicolumn{7}{|c|}{$\begin{array}{l}\text { SAM } \\
(1-5)\end{array}$}} \\
\hline & & & & & & \\
\hline & Valence & 5.0 & 5.0 & 5.0 & 5.0 & 4.75 \\
\hline & Arousal & 4.6 & 4.0 & 4.8 & 4.75 & 3.5 \\
\hline & Dominance & 5.0 & 5.0 & 4.2 & 4.5 & 5.0 \\
\hline
\end{tabular}


most mentioned actions towards savings resulting from the activity. A student reported taking the chronometer to the bathroom to measure the showering time, one of the most valuable behaviours towards savings in that scenario.

Another student brought some educational content provided by the public agents in the past and asked the teacher to explore it with colleagues in the classroom. This is an evidence of the study impact on raising energy awareness not only among the participants, but also within their social groups.

\subsubsection{Involving stakeholders}

At school, the presence of the tree in a gathering area was an important element that impacted the social group beyond participant students, eliciting the topic among other teachers and raising other students' interest to be part of the activity.

Publishing the challenges creation and achievements on Facebook with pictures of the groups, when authorised by the parents, revealed to be an important tool to engage the family. Some students spontaneously took note of the Facebook address to show to the parents. Attracted by seeing and sharing pictures of the children, some started to follow the online activities. Others called the school asking more details about the tree functioning after seeing it on Facebook. It is worth mentioning that around $77 \%$ of Internet users in Brazil have a Facebook account (IDG Now 2013).

A sample of five parents/guardians was interviewed. All of them mentioned that the child explained about the tree functioning to the family and asked for their help to read the energy meter, except the participant with the smart meter, who explained about it to the family instead. The mother of a participant who did not bring any reading admitted that the reason was that the house had been without energy during that time due to the non-payment, creating some embarrassment to the child. Another parent admitted having an illegal connection.

All the others reported that the children were aware of their consumption during all the study and were requiring other people's attention for savings: "every time she sees something turned on, she says "no... my tree needs to be lightened!”, reported a parent.

However, not all effort by the children was welcome in their homes. One parent said to feel annoyed by the child behaviour: "she tries to convince us all the time, but nobody listen to her (...) we are tired when we get back home, and we don't want to pay attention to that". Another parent told that the child behaviour incited a fight among the family. An uncle, who is the one responsible for paying the energy bill, complained about the children alerts about waste.

\section{Discussion}

Targeting to promote a new way of perceiving energy consumption within a social group implies developing a common understanding of energy generation and the environmental impact, as well as building a collective knowledge around possibilities to review usual consumption habits, in line with the social group's socio-economic reality.

Built to mediate this social change process, the SEET design and evaluation constantly dealt with the interplay of technical and social aspects. Figure 12 represents these aspects involved in the study, mapped according to the metaphor of the "semiotic onion", a representation from the organisational semiotics (OS) (Liu 2000), in line with the socially aware design approach (Baranauskas 2014).

Analysing the dialogue among the three levels "of the onion", technical, formal, and informal, helps to understand the systemic view of the situated technology and the whole scenario.

In the core of the technical level is the energy tree. Results indicated that the tree itself was not the main reason for the high motivation (according to the design elements evaluation). Instead, it worked as a trigger for the subject under discussion. According to Fogg (2009), triggers are important to persuade people by means of a technology. In particular for being placed in a social area (the library), the tree represented the need to collaborate to achieve a result. The interactive system properly played its part in formalising the groups' agreements and actions towards the collaboration. The evaluation of the interactive system revealed that it was adequate to students' skills, leading to a positive emotional response.

Between the technical and formal levels, the energy meters represented not only the connection with real consumption and everyday actions, but also they suggested the study is not an isolated initiative, but part of a bigger action in association with the energy provider

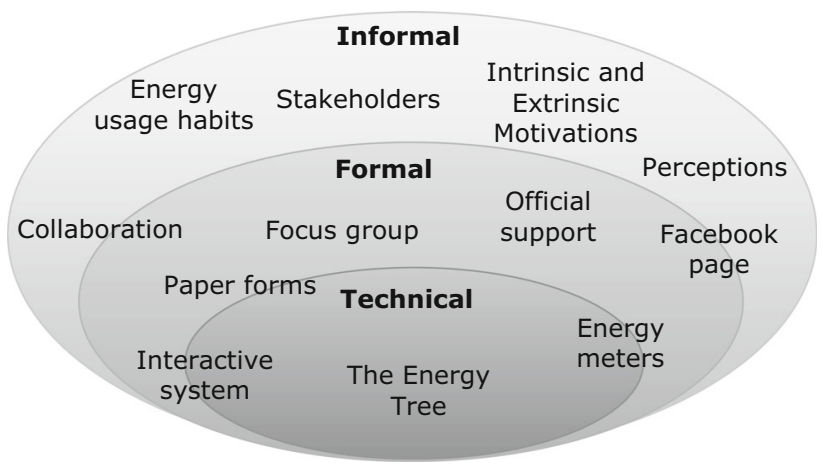

Fig. 12 "Semiotic onion" with the elements that contributed to raise energy collective awareness 
(official support). Technical aspects of the meters, though, strongly influenced the dynamics of the study. The fact of the meters in the participants' households were not standardised and were not updated to the smart technology as expected led to high levels on data inaccuracy. But, instead of being a constraint to the activities, having to read the meter daily was a positive aspect to engage the students and their family, considering children needed help from adults to make the readings.

Consequently, the tree representing engagement instead of savings worked better to the main target of raising energy awareness. As also stated by Johnson et al. (2012), dealing with imprecise measurements and baselines are critical factors that make the savings calculation unreliable. Ideally, the criteria to calculate the feedback of the tree should consider two dimensions, savings, even being symbolic, and engagement.

Also dialoguing with formal aspects, the paper forms providing suggestions for savings and for annotating the readings had a crucial role to keep the activities flowing during the week. They made the activity tangible, reminding students about visiting the meters daily, and made clear the sense of responsibility from them in keeping the paper for many days. They considered the form as a necessary tool for being active in the study.

The focus group is in the formal level. It promoted the opportunity for sharing initial and final perceptions also playing a role in building a collective knowledge. This new way of perceiving energy was then translated into actions of reviewing individuals' habits of consumption, negotiated among the groups to set the challenges, formalised in the paper forms (individually) and in the interactive system (collectively). The Facebook page, between formal and informal level, documented the dynamics, made the challenge a public commitment, and bridged the participation in the school with parents and other people (stakeholders) in the social group.

Intrinsic and extrinsic motivations are informal elements. Considering the high level of intrinsic motivation assessed, it is possible to assume that the SEET design and the experimental setup were adequate for the participants. Promoting identity for the groups, the technical novelty, fun aspects in the dynamics, the feasible targets for savings, and the group work can be considered motivational aspects of the SEET. Changing the current dynamics in order to involve everyone in the control of the interaction, thus, is an aspect that might be improved to strength individual commitment.

The intended collaborative aspect of the SEET was clearly understood, as observed during the negotiation when creating the challenge and along the interaction. However, the competition aspect emerged spontaneously even not being intentionally promoted. As also reported in the literature (Johnson et al. 2012; Froehlich et al. 2010), it was an external force to engage users but with side effects. A student reported that he opened the circuit breaker of the house for having significant savings, since his family was not willing to contribute. As similarly reported by Johnson et al. (2012), it demonstrated interest and engagement but will not necessarily change his energy awareness or his attitude towards conservation. The motivation assessment also confirmed the participants' interest for being rewarded. According to Piccolo and Baranauskas (2012a, 2012b), rewards can be an interesting trigger but cannot be considered as a longer-term incentive. Participants must see the intention behind the reward to be considered intrinsically motivated.

The emotional response and motivational assessments suggested a very positive perception of the study by the participants, which was reinforced by answers to the final questionnaire and the final focus group. The cloud tag in Fig. 13 represents the most frequent words in the answers. Cool, Saving, Love it and Liked it are highlighted. The positive affective feedback was reinforced by thank-you cards offered by the students to the researchers, as illustrated in Fig. 14. In detail, the card on the top right refers to the value of learning about saving energy and environmental protection (in Portuguese), while the one in the bottom represents the tree $100 \%$ completed.

\subsection{Challenges in a developing country scenario}

How people in this social group perceive sharing information, collaboration, their typical consumption and how they relate with the energy provider were some of the aspects previously investigated that led to the SEET architecture (Piccolo and Baranauskas 2012a, 2012b; Piccolo and Baranauskas 2013). Considering these aspects certainly facilitated the reflection overall SEET system by the users.

Even though these and other socio-economic and cultural characteristics were analysed and considered to inform technology design, interventions in real-life

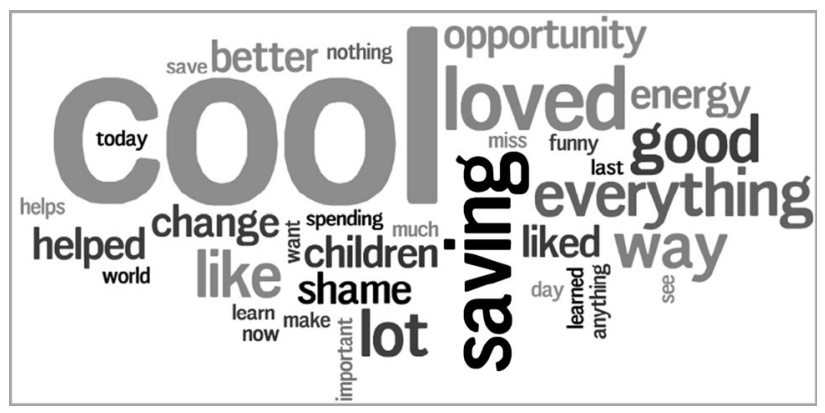

Fig. 13 Cloud tag of participants' feedback 


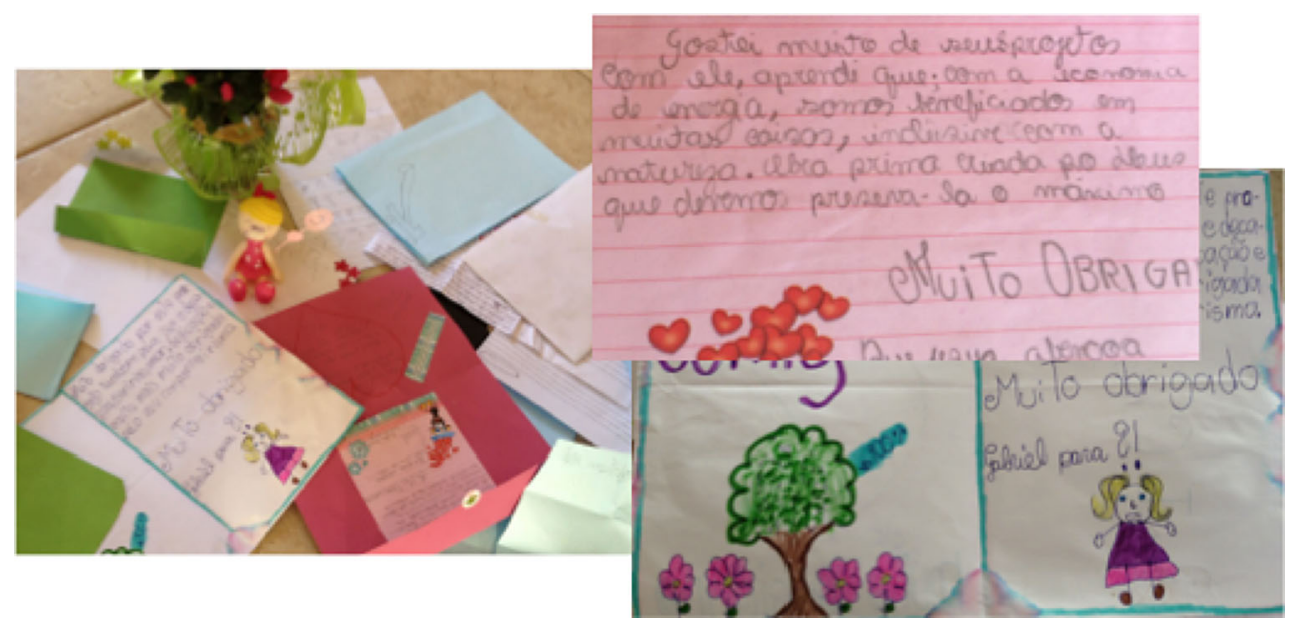

Fig. 14 Thank-you cards offered by the participants

environment, or "in the wild" (Roger 2011), are influenced by a multitude of interplaying variables and conditions. The extent these conditions can affect the activities is hard to be predicted, requiring from the researcher to deal with unexpected variables to keep the study under control.

Fraud to steal energy is a practice culturally accepted in some areas of Brazil and expected to be found to a certain degree in the scenario of this study too. The new physical network connecting households and the utility, part of the smart-grid deployment, though, intended to deal with this reality as an opportunity to welcome as regular costumers people who did not use to pay for the energy consumed, without judgment or punishment (Piccolo et al. 2011). The SEET should add a positive element to the reflection on the issues of these people too.

Even being centrally located in the area planned to deploy smart grid, a great part of the students belong to a less privileged social group in the neighbourhood and for this reason were not prioritised by the energy provider staff to get the new smart meters, although technically and formally considered by the government project.

The invitation to participate was sent to the parents in advance requiring from them to inform the official number of the meter, suggesting that a connection with the utility database would be made. This fact prevented more people to participate. According to the school staff, the main reason why only 24 out 40 families accepted to join was the existence of fraud. Some students, though, wanted to join in any circumstance, raising the discussion around illegal connections at school. It required from teachers, the school director, researchers, and parents, to bring this topic into discussion with the students in general, and deal with the values involved in the question. Not judging, but evidencing the advantages of being regular consumers (safety, quality of service, eventually lower price, etc.), was the posture adopted by the school and the researchers.

If the extent of the situated problem was known in advance, an association with the utility could be made in order to provide an opportunity for these households to be welcome as legal customers if they desired to (Piccolo and Baranauskas 2011). But the reason why most of households did not receive the meters is not simple either. According to local people (utility and school staff), it can be associated with the drugs trafficking in the area, which sometimes assumes the control of the social group as a parallel power, intimidating both the presence of the utility's staff in the area, and the society of speaking openly about their social problems.

From the teacher's perspective, this social pressure and the eventual involvement of some family members with drugs traffic also affect the expected support from the family to the children's school life, and could be the reason why some strongly motivated students struggled to properly obtain the readings.

When interviewed about their perception of the study, both a teacher and the educator responsible for the school mentioned the social problem of illegal energy connection that prevented some students to participate and the consequent bad feeling. Despite that, both stated the desire to repeat the experience with other groups, due to the valuable discussions and positive involvement. They actually highlighted the motivational impact of the tree that triggered more than interest but excitement by the students during all the week. "The interest and responsibility of the kids were impressive!", said the teacher. Representatives of the Secretary of Education from the city council visited the intervention invited by the school officers to witness the positive involvement. The families' involvement, particularly via Facebook, was another positive surprise for the 
school staff. Excepted by one participant, the parents in general did not express any concern in sharing the activity on social media. Actually, they approved the initiative and recognised the value on sharing "good examples".

Although the participation and enthusiasm were generally high, some students demonstrate a sense of frustration for not being able to fully motivate the families' engagement. Additional artefacts or tools could also be developed to empower students when spreading the message to the family members in the household. Online games that engage the family are examples of strategy that could motivate people that are indifferent to energy conservation (Piccolo and Baranauskas 2011).

\subsection{Limitations of the study and their implications}

The real-world scenario of the study brought some constraints related to data accuracy that limited contributions; nevertheless, the same scenario showed us conditions that could not have been anticipated and are essential to any real action to be effective regarding the subject addressed (the concept of energy, energy saving, energy relation to the technology and the environment).

Although technical and social issues prevented the original plan to be executed with the energy tree providing feedback of savings, the engagement was in general very positive, and the adaptation required to feedback engagement instead fits better the purpose and the scenario of the intervention. The original idea of calculating savings to light on the tree would be still possible in a homogeneous scenario in terms of types of meters, in larger scale and/or longer term, minimizing the effect of external events. Areas with higher consumptions more likely to waste energy are more suitable to the original purpose of the tree.

Comparing interest and engagement between households with the smart meter and those without it might lead to interesting results, but the small number of participants with smart grid at home restricted such analysis that can be part of further investigations.

Another constraint of the study was the impossibility to associate consequences of individual consumption to a direct representation in the tree due to the extreme low level and imprecise savings calculations. Despite that limitation, the potential to discuss effects of minor behaviours and the capability to raise energy awareness were preserved, mainly due to the collaborative aspect of the activity.

Although change behaviour effectively can be considered the final target of an eco-feedback technology such as the SEET, this study concentrated the efforts on the first step of this process, which is raising awareness in a social group. The lessons learned with regard to the elements that contributed to raise collective awareness, mostly assigned to fostering collaboration among participants and their social group than to technological innovation, can be adapted to other similar initiatives.

\section{Conclusion}

This paper reported and discussed results of an exploratory study on a Socially-inspired Energy Eco-Feedback Technology (SEET), aiming at promoting energy awareness collaboratively by means of an interactive system and a tangible artefact. Motivational aspects from psychology and local sociocultural data informed the SEET design, which was evaluated with a group of students from an elementary school located in a developing region.

The tree (tangible and virtual) as a feedback was an essential element to trigger motivation, but some daily commitments (reminded by the paper to be filled out) kept it going on. The need of collaboration to achieve significant results was a message clearly perceived and promoted by participants. Despite the families' involvement, students did not feel empowered enough to change the way of thinking of their family. Competition among groups naturally emerged, reinforcing the need to better understand the potential of group dynamics for promoting a social change.

Considering contextual cultural and socio-economic aspects was crucial to properly setup the technical solution. Even so, the investigation wild scenario shaped the way the study was conducted, for example, required a change in the meaning of the feedback provided by the energy tree from savings to engagement and revealed conditions that could not have been anticipated, and are essential to any real action to be effective regarding the energy relation to the technology and the environment.

The SEET demonstrated to be effective to raise awareness in this research scenario, and beyond that, brought to discussion important social aspects among the participants. Many of these social aspects revealed are actually shared with a considerable part of the Brazilian society. The role the technology can play, though, and how it might change within different social groups are aspects preliminarily signalled to be further explored in other studies.

Acknowledgments We thank the Escola Jovelino Lanza staff, CEMIG, Microsoft Research, CNPq, CAPES, and FAPESP for support and funding. Lucas Yamashita for the development and support, and especially the students and their families for the engagement.

Open Access This article is distributed under the terms of the Creative Commons Attribution 4.0 International License (http:// creativecommons.org/licenses/by/4.0/), which permits unrestricted use, distribution, and reproduction in any medium, provided you give appropriate credit to the original author(s) and the source, provide a link to the Creative Commons license, and indicate if changes were made. 


\section{Appendix}

See Tables 2 and 3.

Table 2 Tabulation of the Elementary School Motivation ScaleEMS applied in groups

\begin{tabular}{lll}
\hline & Mean & SD \\
\hline Intrinsic motivation & 4.6 & 1.02 \\
I like using the Energy Tree & 4.6 & 0.49 \\
Using the Energy Tree interests me a lot & 5.0 & 0.00 \\
I want to use it even when I don't have to & 4.2 & 1.60 \\
Identified regulation & 4.7 & 0.44 \\
I can learn many things using the Energy Tree & 5.0 & 0.00 \\
I choose using the Energy Tree to learn many things & 4.8 & 0.40 \\
In life, it's important to learn how to use technology & 4.4 & 0.49 \\
Controlled regulation & 3.7 & 1.53 \\
I use the Energy Tree to get a nice reward & 3.8 & 0.98 \\
I use the Energy Tree to please my parents or my & 3.2 & 1.83 \\
$\quad$ teacher & & \\
I use the Energy Tree to show how good I am & 4.0 & 1.55 \\
\hline
\end{tabular}

Table 3 Summary statistics of the intrinsic motivation inventory

\begin{tabular}{lllll}
\hline & Mean & Median & Mode & SD \\
\hline Interest/enjoyment & 6.48 & 7.00 & 7.00 & 1.54 \\
Perceived competence & 6.09 & 7.00 & 7.00 & 1.84 \\
Pressure/tension & 2.98 & 1.00 & 1.00 & 2.54 \\
\hline
\end{tabular}

\section{References}

Accenture (2010) Understanding consumer preferences in energy efficiency. http://goo.gl/MQqa7B (2011)

ANEEL Bandeiras Tarifárias (in Portuguese) (2014) http://www. aneel.gov.br/area.cfm?idarea $=758$

Baranauskas MCC (2014) Social awareness in HCI. ACM INTERACTIONS July-August 2014, pp 66-69

Boucher A, Cameron D, Jarvis N (2012) Power to the people: dynamic energy management through communal cooperation. In: Proceedings of DIS' 12 . ACM, pp 612-620

Bradley M, Lang P (2000) Measuring emotion: behavior, feeling, and physiology. In: Cognitive neuroscience of emotion. Oxford University Press, New York, pp 242-276

Brazil (2014) Ten year plan for energy expansion (PDE 2023). http:// www.epe.gov.br/PDEE/Forms/EPEEstudo.aspx

Brewer RS, Lee GE, Johnson PM (2011) The Kukui cup: a dorm energy competition focused on sustainable behavior change and energy literacy. In: Proceedings of HICSS

Chorianopoulos K, Spinellis D (2006) User interface evaluation of interactive TV: a media studies perspective. Universal Access in the Information Society 5, 2, Springer, pp 209-218

Cohen C et al (2005) Energy requirements of households in Brazil. Energy Policy 33(4):555-562

Computer Technology Institute (2012) Real-time monitoring of energy consumption into 50 schools. http://gen6.sch.gr/index.php/en/
Deci EL, Ryan RM (1985) Intrinsic motivation and self-determination in human behavior. Plenum, New York

Dillahunt T et al (2009) It's not all about "Green": energy use in lowincome communities. In: Proceedings of the 11th international conference on ubiquitous computing (Ubicomp '09). ACM, pp 255-264

Facebook alcança melhor marca no Brasil com 76 milhões de usuários. IDG Now (2013) http://goo.gl/ngfhel (in Portuguese)

Fogg BJ (2009) A behavior model for persuasive design. In: Proceedings of persuasive ' 09 , ACM, Article 40

Froehlich $\mathrm{J}$ et al (2012) The design and evaluation of prototype ecofeedback displays for fixture-level water usage data. In: Proceedings of CHI'2012, pp 2367-2376

Froehlich J, Findlater L, Landay J (2010) The design of eco-feedback technology. In: Proceedings of CHI'10, pp 1999-2008

Guay F et al (2010) Intrinsic, identified, and controlled types of motivation for school subjects in young elementary school children. Br J Educ Psychol 80:711-735

Hall ET (1959) The silent language. Anchor Books, New York

Hayashi ECS, Khater RMM, Baranauskas MCC (2012) Affective aspects of the experience with low cost laptops in educational context. In: Proceedings of the IASTED International conference computers and advanced technology in education, pp 63-68

Hayashi ECS, Piccolo LSG, Baranauskas MCC (2013) Perspectives on the evaluation of affective quality in social software. Int $\mathrm{J}$ Web Based Commu IJWBC 9(4):519-534

He HA, Greenberg S, Huang EM (2010) One size does not fit all: applying the transtheoretical model to energy feedback technology design. In: Proceedings of CHI' 2010, ACM, pp 927-936

Holmes TG (2007) Eco-visualization: combining art and technology to reduce energy consumption. In: Proceedings of $\mathrm{C} \& \mathrm{C}$ '07, ACM, pp 153-162

IBGE. Cities (2015) http://cidades.ibge.gov.br (Sete Lagoas Human Developmen Index)

Johnson PM et al (2012) Beyond kWh: myths and fixes for energy competition game design. Meaningful play conference, East Lansing

Jönsson L, Broms L, Katzeff C (2010) Watt-lite: energy statistics made tangible. In: Proceedings of DIS '10, pp 240-243

Katzeff C, Nyblom A, Tunheden S, Torstensson C (2012) Usercentred design and evaluation of EnergyCoach-an interactive energy service for households. Behav Inf Technol 31(3)

Kuznetsov S, Paulos E (2010) UpStream: motivating water conservation with low-cost water flow sensing and persuasive displays. In: Proceedings of CHI '10, pp 1851-1860

Liu K (2000) Semiotics in information systems engineering. Cambridge University Press, Cambridge

Neustaedter C, Bartram L, Mah A (2013) Everyday activities and energy consumption: how families understand the relationship. In: Proceedings of CHI '13, pp 1183-1192

Petkov P et al (2012) Personalised eco-feedback as a design technique for motivating energy saving behavior at home. In: Proceedings of NordiCHI'12, ACM, pp 587-596

Piccolo LSG, Baranauskas MCC (2011) Motivational aspects in energy feedback systems design. In: Proceedings of IHC + CLIHC 2011, pp 313-328

Piccolo LSG, Baranauskas M (2012a) Basis and prospects of motivation informing design: requirements for situated ecofeedback technology. In: Proceedings of the 11th Brazilian symposium on human factors in computing systems (IHC'12), SBC, pp 137-146

Piccolo LSG, Baranauskas MCC (2012b) Energy, environment, and conscious consumption: making connections through design. In: Proceedings of the 11th Brazilian symposium on human factors in computing systems (IHC'12), SBC, pp 147-150 
Piccolo LSG, Baranauskas MCC (2013) Climbing the ladder with energy: informing the design of eco-feedback technology with a social approach. In: Proceedings of the 14th international conference on informatics and semiotics in organisationsICISO'13, Springer, pp 185-194

Piccolo LSG, Scharl A, Baranauskas C (2012) Design of ecofeedback technology to motivate sustainable behavior: cultural aspects in a Brazilian context. In: Proceedings of conferenceIRM. International Conference on Information Resources Management. http://aisel.aisnet.org/confirm2012/34

Piccolo L, Hornung H, Baranauskas M, Pereira R (2013) Designing to promote a new social aordance for energy consumption. In Proceedings of 12th IFIP conference on e-Business, e-Services, e-Society, Springer, pp 213-225

Pierce J, Paulos E (2012) Beyond energy monitors: interaction, energy, and emerging energy systems. In: Proceedings of CHI '12. ACM, pp 665-674

Rodrigues DRK, Teixeira AC, Neris VPA (2014) Assessing the elderly's emotional responses while interact with movies enriched with additional multimedia content. Universal Access in Human-Computer Interaction. Aging and Assistive Environments. Lecture Notes in Computer Science, V8518, Springer, pp $155-166$

Rogers Y (2011) Interaction design gone wild: striving for wild theory. Interactions 18(4):58-62

SDT (2014) Intrinsic Motivation Inventory. http://www. selfdeterminationtheory.org/questionnaires/10-questionnaires/50

Stragier J, Derboven J, Laporte L, Hauttekeete L, De Marez L (2013) Kilowhat? A multidisciplinary approach on the development of a home energy management system. Behav Inf Technol 32(11)

United Nations (2015) Development Programme. Human Development Reports http://hdr.undp.org

Vyas D (2012) Domestic artefacts: sustainability in the context of Indian middle class. In: Proceedings of ICIC '12, ACM, pp 119-128

World Bank (2015) Electric power consumption per capita http://data. worldbank.org/indicator/EG.USE.ELEC.KH.PC 